\title{
Implementation of transmural disease management in patients admitted with advanced heart failure
}

\author{
Jürgen DUCHENNE ${ }^{*, 1,2}$, MSc; Frederik H. VERBRUGGE ${ }^{*}, 1,3$, MD; Matthias DUPONT ${ }^{1}$, MD; \\ Jan VERCAMMEN ${ }^{1}$, RN; Linda JACOBS ${ }^{1}$, RN; Lars GRIETEN ${ }^{1,4}, \mathrm{PhD}, \mathrm{MSc}$; \\ Pieter VANDERVOORT ${ }^{1,4}, \mathrm{MD}$; Wilfried MULLENS ${ }^{1,4}, \mathrm{MD}, \mathrm{PhD}$ \\ ${ }^{1}$ Dept. of Cardiology, Ziekenhuis Oost-Limburg, Genk, Belgium; ${ }^{2}$ Dept. of Life Sciences, Faculty of Medicine and Life Sciences, Transnational \\ University Limburg, Hasselt, Belgium; ${ }^{3}$ Doctoral School for Medicine and Life Sciences, Hasselt University, Diepenbeek, Belgium; \\ ${ }^{4}$ Biomedical Research Institute, Faculty of Medicine and Life Sciences, Hasselt University, Diepenbeek, Belgium.
}

*These two authors contributed equally to the manuscript

Objective The objective of this study was to assess the feasibility and impact on readmissions of transmural disease management across the borders of the cardiology department in patients with advanced heart failure (HF).

Methods and results Consecutive patients, readmitted within one year for advanced HF by a dedicated specialist $(n=55)$, were followed for $22 \pm 10$ months after implementation of a hospitalwide transmural disease management strategy. Participants received a tag in their electronic medical record, triggering a HF caregiver contact, with subsequent guideline-recommended, protocol-driven care on each cardiac or non-cardiac hospitalization as well as outpatient evaluation. Upon transition to outpatient follow-up, patients were instructed to call the $\mathrm{HF}$ caregiver with any question at low threshold. Readmission rates were prospectively collected. Despite receiving adequate treatment with neurohumoral blockers, patients $(71 \pm 11$ years; ejection fraction $35 \pm 13 \%$ ) had spent $4 \%$ (27\%) of the year preceding study inclusion in hospital, with $73 \%$ admitted once, $20 \%$ twice, and $7 \%$ more than twice for acute decompensated HF (ADHF). During the study, patients were exposed to $6 \pm 4$ dedicated HF caregiver contacts. Participation in remote device monitoring increased from $31 \%$ to $92 \%$, with $1(0-3)$ additional phone contacts per patient-year of follow-up in this subgroup $(n=24)$. All-cause mortality and readmission rates for ADHF were 10\% and $25 \%$ after one year, and 19\% and 39\% after 2 years, respectively. Follow-up time spent in hospital decreased significantly to $2 \%(16 \%)(P$ value $=0.047)$.

Conclusions Follow-up of advanced HF patients through transmural disease management is feasible and associated with favourable clinical outcome.

Keywords Disease management-heart failure-hospitalization-quality of health care.

\section{INTRODUCTION}

Improvements in pharmacotherapy and innovations in cardiac devices have led to an increased life expectancy and better quality of life in heart failure (HF) patients $^{1-16}$. Yet, despite these advances, HF remains an important cause of morbidity and mortality worldwide.

Address for correspondence:

Frederik Verbrugge, MD, Dept. of Cardiology, Ziekenhuis Oost-Limburg, Schiepse Bos 6, 3600 Genk, Belgium.

E-mail: frederik.verbrugge@zol.be

Received 27 August 2013; accepted for publication 29 October 2013.
It affects $23 \%$ of the total population in developed countries, with a prevalence as high as $20 \%$ in octogenarians ${ }^{17,18}$. Acute decompensated HF (ADHF) is the leading cause of hospital admissions in patients $>65$ years of age, with 60-day mortality and repeat readmission rates close to $15 \%$ and $30 \%$, respectively ${ }^{19}$. Moreover, $\mathrm{HF}$ is a major contributor to health-care costs, consuming about $2.5 \%$ of the total budget, with $60-70 \%$ spent on hospitalizations for $\mathrm{ADHF}^{20,21}$. Therefore, major societies like the Heart Failure Society of America (HFSA), the American Heart Association (AHA), the American College of Cardiology (ACC) and the European Society of Cardiology (ESC) have been engaged in trying to reduce HF readmission rates by implementing better current evidencebased diagnostics, treatments and guidelines ${ }^{17,22}$. 
Regrettably, disease management strategies implemented only at a single specialized HF ward using a one-fits-all approach have failed to improve ADHF readmission rates ${ }^{23}$. Moreover, it is important to acknowledge that $\mathrm{HF}$ is not one specific disease, but rather a complex clinical condition, characterized by diverse cardiac and non-cardiac diseases. Indeed, co-morbid conditions like renal dysfunction, diabetes, or lung disease are very prevalent, and have a major impact on morbidity and mortality $^{24}$. As a result, HF patients frequently present at non-cardiac wards or medical services (i.e., extramural $)^{25}$. Therefore, care for HF patients ideally comprises an individually tailored approach, which should be delivered in a systematic way with each hospitalization (or outpatient contact), irrespectively of the reason for admission, and thus also including non-cardiac hospitalizations (i.e. transmural care). Such a quality of care improvement initiative, focusing on individually tailored HF disease management with transmural care delivery and a central role for the paramedical HF caregiver, was implemented at our centre for advanced HF patients with repeated readmissions. We report the outcome data for patients who were followed by this strategy. More specifically, the impact of the programme on readmission rates and clinical outcome was assessed.

\section{METHODS}

\section{Study population}

From May 2009 until March 2011, we included consecutive patients admitted to a tertiary care centre (Ziekenhuis Oost-Limburg, Genk, Belgium) with a diagnosis of advanced heart failure, who were referred to a dedicated HF specialist (W.M.) for further therapy. Additionally, patients had to be admitted for ADHF at least once during the preceding year. ADHF hospitalizations were defined as hospital admissions because of signs and/or symptoms of congestion and/or low cardiac output. During the hospital stay intravenous diuretics, inotropes and/or vasodilators had to be administered to these patients. The study complied with the declaration of Helsinki and the locally appointed ethics committee approved the study protocol. As the study was only observational, the need for informed consent was waived.

\section{Study efforts to deliver transmural and individually tailored care}

Identifying the patient throughout the hospital

What sets the transmural disease management strategy of this study apart from other multidisciplinary programmes is that real efforts were made to deliver individually tailored HF care across the classical borders of the cardiology ward and even across the hospital (i.e., transmural). Therefore, upon inclusion in the study, all patients received a special tag in their electronic medical record (EMR). This tag was subsequently activated with each hospital readmission or outpatient evaluation and triggered a paramedical HF caregiver contact. Consequently, irrespective of the reason for readmission or location of the patient inside or outside of the cardiology ward, a HF caregiver was notified who visited and evaluated the patient.

Central role for the dedicated paramedical heart failure caregiver

A dedicated team of HF caregivers, all nurses trained in HF pathophysiology, echocardiography, and cardiac devices, played a central role in our disease management strategy. Importantly, these HF caregivers remained at the centre of HF care during and after transition to outpatient follow-up, irrespective of the physician treating the patient: (i) specialized care by the dedicated HF cardiologist; (ii) general cardiology care by the patient's personal cardiologist; and (iii) non-cardiac care including the general practitioner of the patient. Patients were explicitly instructed to contact their HF caregiver for any question at low threshold, during hospitalization (cardiac and non-cardiac) as well after discharge. Moreover, there was a close collaboration with homecare nurses after discharge through one specific contact person, who was informed of the patient's hospitalization and discharge plan. This person instructed the homecare nursing team to follow-up on the patient's weight, blood pressure, heart rate and symptoms, and contacted the HF caregiver with any problem.

\section{Transmural care delivery during hospital admission}

At any time when a patient was visited by the HF caregiver, disease education tailored to the patients' individual needs and conditions was provided. In addition, at least one visit of a dietician, a physical therapist and, if indicated, a psychologist, was arranged before discharge. Compliance with medications and dietary sodium restriction were always evaluated, as instructed by the guidelines ${ }^{17}$. Notes were made in the EMR of the patient about different aspects of the education provided, and points of importance for future care were highlighted. Generally, patients received 6 education moments within the first year after a hospital admission for ADHF: two elaborate education sessions, preferably at least one with the patient's close relatives (ca. 30-45 min); two short education sessions focusing on key points of 
medications and dietary sodium restriction (ca. $8 \mathrm{~min}$ ) and two telephone contacts 2 weeks and 6 months after discharge. Importantly, as the paramedical HF caregiver team had a thorough insight into HF pathophysiology, echocardiography and devices, individually tailored care and education could be provided. Furthermore, the HF caregiver was instructed to check if HF patients with reduced ejection fraction were receiving optimal medical therapy including an angiotensin-converting enzyme inhibitor or angiotensin II receptor blocker, a beta blocker, and a mineralocorticoid receptor antagonist at guideline-recommended tolerated target dosages. If pharmacological treatment could be improved, the HF caregiver would inform the patient's general cardiologist or treating physician in order to increase the dose if appropriate. Similarly, indications for advanced HF therapies could be suggested by the HF caregiver.

If a prolonged hospitalization was needed, the HF caregiver continued to visit the patient at least once every three to five days. Standardized instructions to measure daily weight changes, restrict the use of intravenous fluids and avoid non-steroidal anti-inflammatory drugs if possible were given to non-cardiac nursing teams caring for the patient. Finally, a structured questionnaire was used to assess the need for further evaluation, and eventually advanced treatment was given by the HF specialist (figure 1). Afterwards, the HF specialist would consider the need and strategy for decongestive therapy, advanced HF therapy, and check indications for cardiac devices. At Ziekenhuis Oost-Limburg, patients with cardiac devices are followed through cooperation between the HF specialist, electrophysiologist, cardiac imaging specialist, and dedicated nurses in a multidisciplinary clinic as described before ${ }^{26-28}$.

\section{Transition to outpatient care}

Finally, when the patient was ready for discharge, the HF caregiver provided discharge notes with general information about HF, recommendations for lifestyle adaptations, and a telephone number of the HF caregiver team, which could be contacted during work hours for trouble-shooting in case of questions or problems. In addition, the general practitioner was always informed electronically of any hospitalization or outpatient contact, and if needed, instructed to check the patients' adherence to medication and/or lifestyle adaptations. Patients with an implantable cardioverter/defibrillator (ICD) or cardiac resynchronization therapy (CRT) defibrillator device were invited to participate in remote
Fig. 1 Structured questionnaire used by the heart failure (HF) nurse to evaluate the need for further evaluation by the dedicated HF specialist.

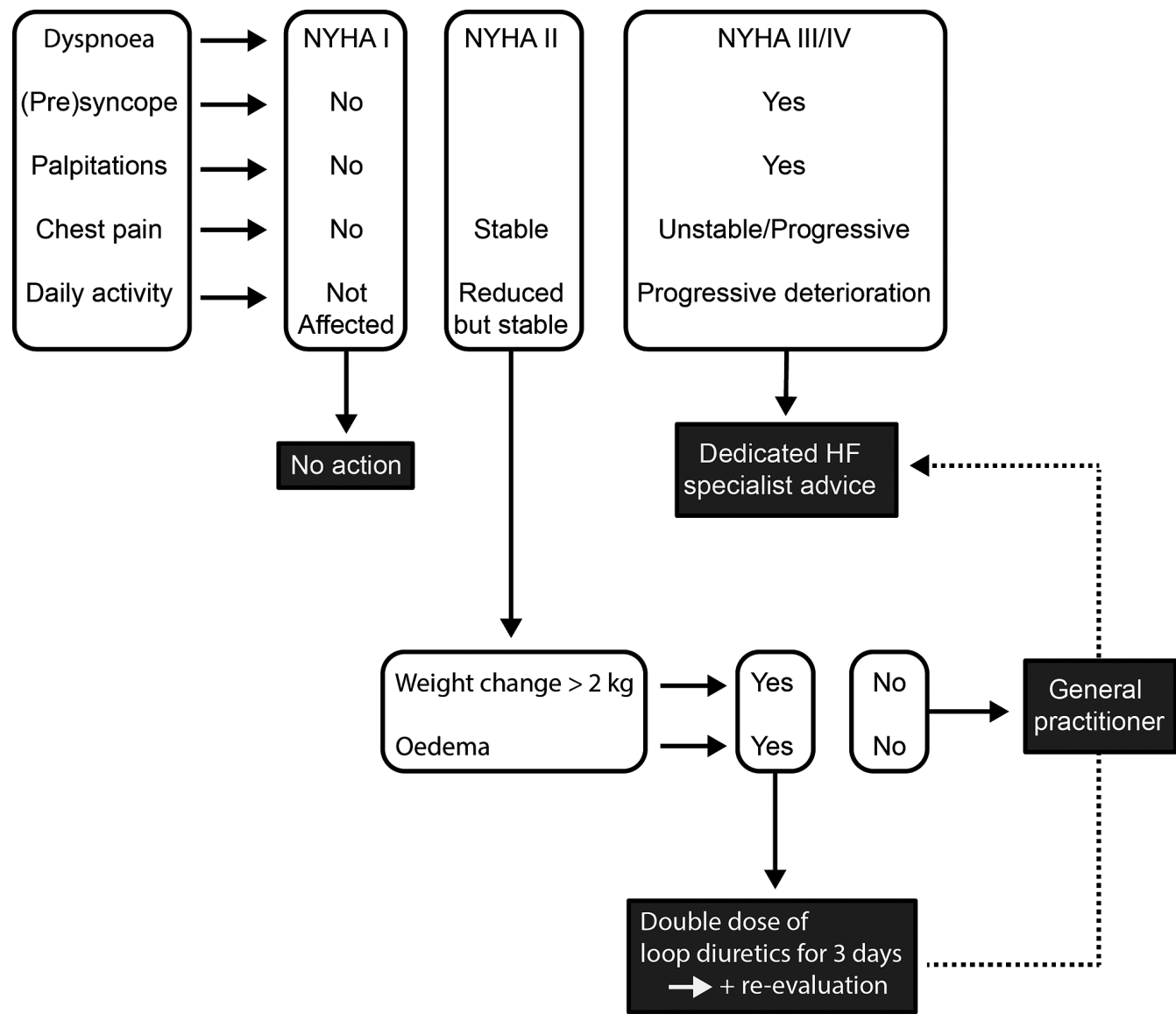


device monitoring. Alarms which prompted action of the HF caregiver included lead/device problems, ventricular and supraventricular arrhythmias, drops in biventricular pacing $<90 \%$ in case of CRT, sudden decreases in heart rate variability, and changes in thoracic impedance in some devices. The dedicated HF caregiver interpreted the alarms daily, with transmissions during weekends read on Monday. Patients were contacted by telephone if alarms were considered to be relevant. The same structured questionnaire used by the HF caregiver for in-hospital evaluation was subsequently employed and HF education provided by phone (figure 1). At each telephone contact, patients were encouraged to contact the HF caregiver team if there was any further change in clinical condition. It is important to state that there was a close collaboration between the HF caregiver team and the general practitioner of the patient, who was informed of every phone call to the patient, and instructed to closely follow-up on recommended treatment adaptations. After 3 days, the HF caregiver made a routine phone call to reappraise the patient's condition.

\section{Study end points}

Demographics, clinical data, medical therapy and admission cause were obtained at the time of the index hospitalization. Changes in medical therapy at hospital discharge and after 6 months of follow-up were registered. A comprehensive assessment was made of different treatment options performed in each patient. Patients were followed until death, their last hospitalization, or their last outpatient evaluation, whichever came last. The primary end point of the study was the readmission rate for ADHF after one and two years of follow-up, excluding elective rehospitalizations. Subsequently, we compared the average yearly readmission rate for ADHF in each individual patient with the year preceding inclusion in the study. The secondary end points were the total number of hospitalizations per year of follow-up and the percentage of follow-up time spent in hospital. Further, time to all-cause mortality was assessed. In addition, the absolute number and type of hospitalizations occurring during follow-up in the study population were prospectively listed. ADHF hospitalizations were subdivided according to their presumed trigger: infection (e.g., respiratory infection), arrhythmia (e.g., atrial fibrillation), noncompliance which also included substance abuse or ADHF because of non-steroidal anti-inflammatory drug use, or an unknown trigger. Acute cardiac hospitalizations were classified as an acute coronary syndrome, a primary diagnosis of arrhythmia, or a miscellaneous cause. Other non-elective hospitalizations were considered to be comorbidity-related. Causes of elective hospitalizations included: implantation of a CRT device, implantation of a pacemaker or ICD, right heart catheterization with/ without subsequent haemodynamic-guided therapy, an electrophysiological procedure (i.e., ablation, electrical reconversion or electrophysiological diagnostics), or another non-specified cause.

\section{Statistical analysis}

All continuous variables were expressed as mean \pm standard deviation (SD), if normally distributed, or otherwise as median (interquartile range, IQR). Categorical variables were expressed as percentages. The primary and secondary end points were compared using the Wilcoxon signed-rank test. Statistical significance was set at a two-tailed probability level of $\alpha<0.05$. Actuarial survival rates were calculated according to the Kaplan-Meier method. All statistical analyses were performed using IBM ${ }^{\circ}$ SPSS (version 20.0) for Windows.

\section{RESULTS}

\section{Study population}

Fifty-five patients met the inclusion criteria and had at least one ADHF hospitalization during the year preceding the index hospitalization. Baseline characteristics of the study population are presented in table 1 . The median (IQR) length of index hospital stay was 7 days (4-10 days) and reasons for admission are presented in table 2. Patients had a mean \pm SD follow-up of $22 \pm 10$ months.

\section{Care strategies during follow-up}

Patient education

During the study period, the 55 study patients had a total of $570 \mathrm{HF}$ education moments by dedicated caregivers resulting in $6 \pm 4 \mathrm{HF}$ caregiver contacts per patientyear of follow-up. Forty-two percent of these contacts took place during hospitalization ( $27 \%$ while being admitted at the cardiology ward, i.e. intramural; $15 \%$ extramural), while $58 \%$ were in an outpatient setting. The median (IQR) time spent by the HF caregiver on an education contact was 31 (12-39) minutes in case of an intramural hospitalization, 10 (5-10) minutes for an extramural hospitalization and 15 (10-15) minutes for an outpatient contact. An additional 20-min education session was provided to patients who received a cardiac device, and another 10-min session was performed to explain the concept of remote device monitoring if the patient participated in remote follow-up. Involvement of the treating physician was minimal and protocol-driven (figure 1). 
Table 1 Baseline characteristics of the study population $(n=55)$

\begin{tabular}{|c|c|}
\hline Age (year) & $71 \pm 11$ \\
\hline \multicolumn{2}{|l|}{ Gender } \\
\hline Male & $73 \%$ \\
\hline Female & $27 \%$ \\
\hline Body mass index $\left(\mathrm{kg} / \mathrm{m}^{2}\right)$ & $28 \pm 6$ \\
\hline \multicolumn{2}{|l|}{ Blood pressure $(\mathrm{mmHg})$} \\
\hline Systolic & $126 \pm 22$ \\
\hline Diastolic & $70 \pm 13$ \\
\hline Heart rate (bpm) & $82 \pm 24$ \\
\hline QRS width (ms) & $129 \pm 42$ \\
\hline QRS width $\geq 150 \mathrm{~ms}$ & $36 \%$ \\
\hline Left ventricular ejection fraction (\%) & $35 \pm 13$ \\
\hline Left ventricular ejection fraction $<40 \%$ & $67 \%$ \\
\hline Mitral valve regurgitation $\geq 2 / 4$ & $46 \%$ \\
\hline Tricuspid valve regurgitation $\geq 2 / 4$ & $29 \%$ \\
\hline Ischaemic heart disease & $59 \%$ \\
\hline \multicolumn{2}{|l|}{ History of cardiac surgery } \\
\hline Coronary artery bypass graft & $22 \%$ \\
\hline Valvular surgery & $19 \%$ \\
\hline History of atrial fibrillation & $60 \%$ \\
\hline Diabetes mellitus & $31 \%$ \\
\hline Chronic obstructive pulmonary disease & $33 \%$ \\
\hline \multicolumn{2}{|l|}{ New York Heart Association functional class } \\
\hline I & $4 \%$ \\
\hline ॥ & $29 \%$ \\
\hline III & $62 \%$ \\
\hline IV & $5 \%$ \\
\hline Maximal aerobic capacity (mL/min/kg) & $12.6 \pm 2.9$ \\
\hline \multicolumn{2}{|l|}{ Cardiac device } \\
\hline Implantable cardioverter/defibrillator & $42 \%$ \\
\hline Cardiac resynchronization therapy & $21 \%$ \\
\hline Serum haemoglobin $(g / L)$ & $12.5 \pm 2.0$ \\
\hline eGFR $\left(\mathrm{mL} / \mathrm{min} / 1.73 \mathrm{~m}^{2}\right)$ & $56 \pm 25$ \\
\hline Plasma NTproBNP (pg/mL) & $3,655(2,3108,832)$ \\
\hline
\end{tabular}

Table 2 Reason for the index hospitalization

$\begin{array}{lr}\text { Acute decompensated heart failure } & 51 \% \\ \text { Non-elective hospitalization not due to heart failure } & \\ \text { Cardiac arrhythmia } & 5 \% \\ \text { Infectious disease } & 2 \% \\ \text { Miscellaneous* } & 13 \% \\ \text { Elective hospitalization } & \\ \text { CRT implantation } & 22 \% \\ \text { Right-sided cardiac catheterization } & 4 \% \\ \text { Electrophysiological procedure (ablation, reconversion, } & 3 \%\end{array}$

$51 \%$

$5 \%$

$2 \%$

$13 \%$

$22 \%$

$4 \%$

$3 \%$

*Pleural effusion, pacemaker erosion, chest pain.

CRT: cardiac resynchronization therapy.

\section{Pharmacological therapy and haemodynamic-guided therapy}

An overview of changes in pharmacological therapy during the index hospitalization and subsequent followup including the use of neurohumoral blockers and vasodilator therapy is provided in table 3. Haemodynamic-guided therapy through guidance by pulmonary artery catheter measurements, with titration of sodium nitroprusside and intravenous diuretics to achieve a central venous pressure $\leq 8 \mathrm{mmHg}$ and pulmonary capillary wedge pressure $\leq 15 \mathrm{mmHg}$ as described before, was performed in 14 patients (25\%) after inclusion ${ }^{29,30}$. This treatment strategy was used in only 4 patients (7\%) before inclusion in the study.

Table 3 Pharmacological therapy

\begin{tabular}{lccc} 
& Baseline & Discharge & After 6 months of follow-up \\
\hline ACE-I & $53 \%$ & $49 \%$ & $43 \%$ \\
Dose (\% of the recommended target dose) & $50(25-63)$ & $50(50-100)$ & $50(50-100)$ \\
ARB & $11 \%$ & $16 \%$ & $19 \%$ \\
$\quad$ Dose (\% of the recommended target dose) & $50(25-50)$ & $25(19-50)$ & $38(25-50)$ \\
ACE-I or ARB & $62 \%$ & $60 \%$ & $50(28-100)$ \\
$\quad$ Dose (\% of the recommended target dose) & $50(25-50)$ & $50(25-75)$ & $91 \%$ \\
Beta blocker & $87 \%$ & $91 \%$ & $50(25-100)$ \\
$\quad$ Dose (\% of the recommended target dose) & $50(25-94)$ & $50(25-56)$ & $58 \%$ \\
Mineralocorticoid receptor antagonist & $51 \%$ & $56 \%$ & $75 \%$ \\
Loop diuretic & $80 \%$ & $89 \%$ & $40(40-80)$ \\
$\quad$ Dose (mg furosemide eq.) & $40(40-80)$ & $40(36-80)$ & $26 \%$ \\
Hydralazine & $20 \%$ & $31 \%$ & $75(38-113)$ \\
$\quad$ Dose (mg) & $50(38-200)$ & $75(50-200)$ & $13 \%$
\end{tabular}

ACE-I: angiotensin-converting enzyme inhibitor, ARB: angiotensin II receptor blocker. 


\section{Elective hospitalizations}

Thirteen patients (24\%) had a total of 17 elective rehospitalizations ( 0.18 per patient-year of follow-up). A detailed description of the reasons for such hospitalizations is provided in table 4 .

\section{Remote monitoring}

At the moment of the index hospitalization, 16 patients had an ICD or CRT defibrillator and only 5 were followed by remote device monitoring (31\%). After inclusion in the study, there was a clear increase of participation as all but one patient agreed to be followed within the remote monitoring programme. Moreover, another 9 out of 10 patients who received an ICD or CRT defibrillator after inclusion participated as well, resulting in an overall participation of $92 \%$. The 24 patients who were followed with remote device monitoring were contacted 95 times in total during the study period, resulting in 1 (0-3) phone contact per patient-year of follow-up. A detailed description of the reasons for remote monitoring phone contacts and subsequent actions is presented in table 5 .

\section{Primary and secondary end points}

The readmission rate for ADHF after one year of follow-up was $19 \%$. After two years, this figure increased to $39 \%$. Compared to the year preceding inclusion, the median (IQR) number of ADHF hospitalizations per patient per year decreased significantly from $1(1-2)$ to 0 $(0-1)(P$-value $<0.001$; figure 2$)$. However, patients who still experienced readmissions for ADHF had a substantially higher yearly hospitalization rate of 1 (1-2). The overall yearly all-cause hospitalization rate decreased significantly from 2 (2-3) before to 1 (0-3) after inclusion in the programme $(P$-value $=0.014)$. As a result, the percentage of follow-up time spent in the hospital also decreased from $4 \%(27 \%)$ in the year before to $2 \%(16 \%)$ after inclusion $(P$-value $=0.047)$. Freedom from all-cause mortality was $90 \%$ after 1 year and $81 \%$ after 2 years of follow-up.

\section{Hospitalization causes}

ADHF hospitalizations accounted for $30 \%$ of all nonelective hospital readmissions. Triggers for ADHF were diverse, but in 55\% no clear cause could be identified and non-compliance was carefully excluded in these cases (figure 3). Acute cardiac hospitalizations accounted for $11 \%$ of non-elective hospital admissions ( $2 \%$ acute coronary syndrome; $6 \%$ arrhythmia; $3 \%$ miscellaneous). The remaining $59 \%$ of non-elective hospitalizations were co-morbidity-related (22\% within and $37 \%$ outside of the cardiology ward).
Table 4 Reason for elective rehospitalizations

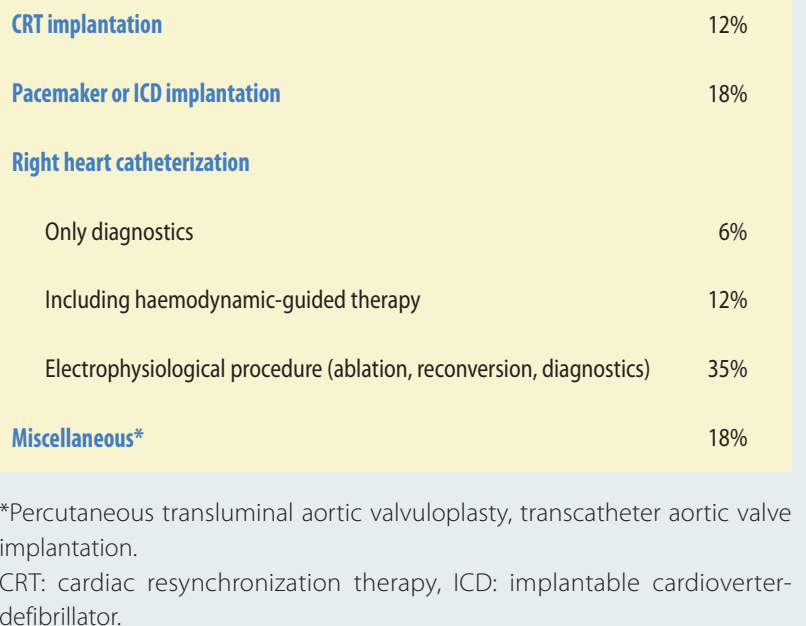

Table 5 Reasons and actions for remote monitoring contact

\begin{tabular}{lr} 
Thoracic impedance alarm & $70 \%$ \\
Education provided, no further action necessary & $45 \%$ \\
Outpatient evaluation by general practitioner and increased diuretics & $31 \%$ \\
Outpatient evaluation by dedicated HF specialist & $24 \%$ \\
Semi-urgent hospitalization & $2 \%$ \\
Arrhythmia & $11 \%$ \\
Education provided, no further action necessary & $40 \%$ \\
Outpatient evaluation by general cardiologist & $60 \%$ \\
Biventricular pacing < $90 \%$ & $5 \%$ \\
Education provided, no further action necessary & $80 \%$ \\
Outpatient evaluation by dedicated HF specialist & $20 \%$ \\
Lead- or device problem & $7 \%$ \\
Education provided, no further action necessary & $71 \%$ \\
Outpatient evaluation by electrophysiologist & $29 \%$ \\
Patient initiative & $7 \%$ \\
Outpatient evaluation by general practitioner & $60 \%$ \\
Semi-urgent hospitalization & $40 \%$ \\
\hline HF. heart failure. &
\end{tabular}

HF: heart failure

\section{DISCUSSION}

The primary finding of this study is that a transmural disease management programme with individually tailored, supervised HF care across the borders of the cardiology department - within and outside of the hospital - is feasible in clinical practice without significantly increased time investment of physicians. Moreover, the implementation of such a programme, mainly provided by paramedical HF caregivers, resulted in an impressive decrease of ADHF readmissions in patients with advanced HF. Although hospital readmissions for ADHF still accounted for $30 \%$ of the remaining non-elective hospitalizations 


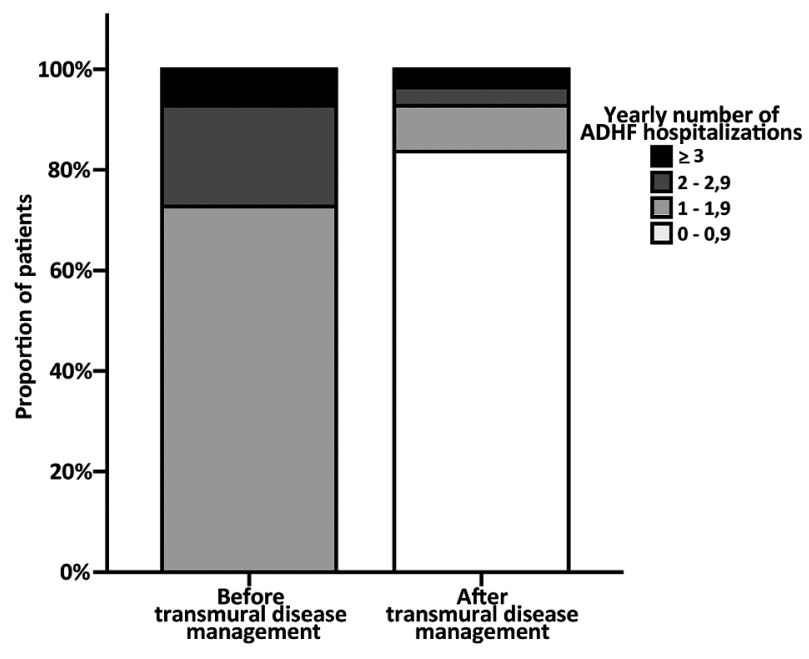

Fig. 2 Yearly number of hospital admissions for acute decompensated heart failure (ADHF) in the study population before and after transmural disease management.

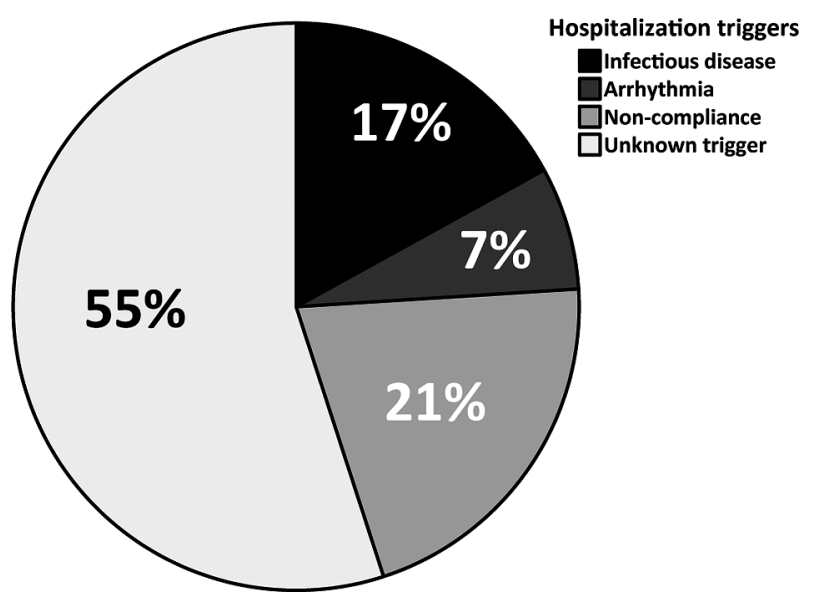

Fig. 3 Triggers for ADHF hospitalizations $(n=42)$.

during follow-up, most of these readmissions were presumably not preventable as they were triggered by infection $(17 \%)$ or lacked a clear trigger with non-compliance excluded as a cause (55\%). Overall, survival was good in this population of very sick patients with HF ( $90 \%$ after one year and $81 \%$ after two years) with only $2 \%$ follow-up time spent in hospital after implementation of the transmural care pathway. Our study strongly suggests that HF care should exceed beyond the boundaries of the cardiology ward. However, to achieve this, an engaged, educated and dedicated team of HF caregivers is pivotal.

As HF is not a simple disease, but an often complex clinical syndrome, care for patients has evolved to comprehensive, integrated and interdisciplinary disease management strategies. The first randomized clinical trial investigating such an approach reported a reduction in the readmission rate of elderly HF patients when comprehen- sive education of patient and family, dietary advice, review of the medication, social service consultation and discharge notes by HF nurses were implemented systematically $^{31}$. Subsequently, several large meta-analyses have confirmed that multidisciplinary disease management strategies in HF patients are associated with a $30 \%$ reduction in $\mathrm{ADHF}$ readmission rates and up to $18 \%$ decrease in the combined event of readmission or death ${ }^{32,33}$. Furthermore, multidisciplinary HF strategies were cost-efficient as the increased cost of organized HF care was offset by a reduction of readmission ${ }^{32-34}$. It is both reassuring and thought-provocative that the implementation of a transmural HF disease management strategy in our study was able to significantly reduce readmission rates, even in old and very sick patients with a high comorbidity burden.

However, an important limitation of randomized clinical trials and meta-analysis evaluating disease management strategies for HF is the substantial variation concerning the design and characteristics of these programmes. Moreover, it is very difficult to assess which aspects of an integrated approach are essential for the perceived benefits. Based on current knowledge, successful strategies probably include a multidisciplinary approach, including in-hospital care, intensive patient education, supportive self-care strategies, optimization of medical treatment, and continued surveillance during follow-up ${ }^{34}$. It should be noted that these aspects were central in our transmural disease management programme. Other key aspects described by others and central in our care strategy, were the active involvement of dedicated caregivers and cardiologists specialized in HF, a close collaboration with the general practitioner, and prompt response on deterioration during follow-up, especially in the patients who participated in remote monitoring. In addition, it should be stressed that HF caregivers in our study were thoroughly trained to have knowledge on HF haemodynamics (clinical assessment and echocardiography), medical therapy and device technology (diagnostics and optimization). These important insights allowed them to really deliver individualized HF care.

Yet, one of the largest randomized clinical trials evaluating a HF disease management strategy, the Coordinating Study Evaluating Outcomes of Advising and Counseling in Heart Failure (COACH) showed disappointing results ${ }^{23}$. In the $\mathrm{COACH}$ study, 1,049 HF patients were randomly assigned to usual care, an interventional group to basic support and an interventional group to intensive support. Patients in the basic support group received visits by a HF nurse at admission and with each outpatient contact. The nurse provided protocol-guided education and a contact address was given in case of clinical deterioration, $\mathrm{HF}$ signs or symptoms. Education materials included a patient diary, brochures on HF and its management and samples of sodium-restricted food seasonings. Patients in the intensive support group received the same interventions as the 
basic support group, but were scheduled for monthly HF nurse visits, weekly telephone contacts in the first month after discharge and were visited at home by a HF nurse. Furthermore, the intensive support also included extra telephone calls, 2 home visits, multidisciplinary advice given by a physiotherapist, dietician and social worker and extra education in HF patient self-efficacy. During followup of 18 months, the study's first primary end point of ADHF readmissions or all-cause mortality did not differ significantly between groups, nor did the second primary end point of number of days lost because of death or hospitalization during follow-up. At first sight, the findings of this study seem in disagreement with previous evidence. However, the COACH study featured a one-size-fits-it-all approach for each individual patient in a specific group. Moreover, HF care delivery was provided only intramurally, while our study clearly demonstrates that through the use of a HF tag incorporated in the EMR of the patient, transmural care delivery is probably more successful at reducing readmissions. This is illustrated by the fact that $63 \%$ of HF caregiver contacts took place outside the borders of the cardiology ward, and $58 \%$ of these even outside of the hospital. Moreover, the substantial proportion of patients who had an ICD or CRT defibrillator $(n=24)$ and were followed with remote monitoring had an additional 1 (0-3) phone contacts per patient-year of follow-up. Indeed, the $\mathrm{COACH}$ investigators acknowledge that $\mathrm{HF}$ disease management programmes should not be abandoned but rather refined. Our study, describing in detail different treatment options and reasons for readmission in a population of very sick HF patients with repeated readmissions, is reassuring as it indicates that with a transmurally delivered, individually tailored, multidisciplinary HF disease management programme, caregivers can actually dramatically reduce readmission rates.

\section{Study limitations}

Some limitations should be acknowledged when interpreting the results of this study. First, this was a singlecentre study in an experienced tertiary care centre, which might create some concerns regarding external validity. However, as explained, we think the concept of transmural disease management is feasible in clinical practice with a simple tag in the EMR, even in less experienced centres, if a motivated team of dedicated and educated heart failure nurses is present. Secondly, the sample size of this study is rather small, implying that our findings are only hypothesis-generating and should be confirmed in larger studies. Yet it remains very difficult to rigorously perform a trial evaluating the impact of a multidisciplinary treatment strategy on clinical outcome. Importantly, our crossover design ensures minimal intra-individual variability and the unequivocally positive results of the study in a selected group of very sick heart failure patients make a strong pledge towards efficacy of the disease management strategy. Thirdly, the sample size of our study was too small to identify the relative effectiveness of different aspects within the disease management programme to improve clinical outcome. Fourthly, despite a strong focus on optimal medical treatment, the proportion of patients who took guideline-recommended neurohumoral blockers increased little during follow-up and the percentage of patients on renin-angiotensin system blockers might be considered low. However, patients were already diagnosed (and treated) for HF before inclusion in the study. Moreover, they were very sick with a median NT-proBNP of $3,655 \mathrm{pg} / \mathrm{mL}$ and a lot of them suffering from chronic kidney disease and not tolerating further uptitration of these medications. Fifthly, $25 \%$ of patients received a CRT device during follow-up, which has been shown to reduce readmissions for ADHF in populations similar to ours ${ }^{13,14}$. However, this effect of CRT in only a subset of patients is unlikely to account for the large drop in ADHF readmissions observed in the population as a whole. Sixthly, because of the inclusion criteria used in our study to select advanced HF patients (at least one hospitalization for $\mathrm{ADHF}$ in the year preceding study inclusion), one might be concerned that regression to the mean bias possibly inflated the effect size of the intervention on the yearly number of ADHF readmissions. However, it should be stressed that patients were followed during $22 \pm 10$ months with the majority of patients followed 2-3 years to minimize this bias. Moreover, the secondary end point of percentage of follow-up time spent in hospital, which is less sensitive to regression to the mean bias, also decreased significantly after inclusion in the study confirming the internal validity of the study.

\section{CONCLUSION}

We report outcome data for a selected cohort of advanced HF patients with repeated readmissions for ADHF, after implementing a hospital-wide, transmural HF disease management strategy. Our data show that if HF care is individually tailored and delivered beyond the borders of the cardiology ward, readmissions for $\mathrm{ADHF}$ and all-cause hospitalizations can be reduced dramatically, even in a population of very sick patients. Moreover, by giving a central role to dedicated HF caregivers, such strategy is feasible in clinical practice as patients are efficiently referred to the most appropriate level of care. This requires close collaboration between general practitioners and other caregivers including but not limited to cardiologists, with patients only referred to the dedicated heart failure specialist for advanced heart failure therapies. 


\section{FUNDING}

No grants, contracts or other forms of financial support were given to support publication of this manuscript. Dr. Verbrugge and Dr. Mullens are researchers for the Limburg Clinical Research Program (LCRP)
UHasselt-ZOL, supported by the foundation Limburg Sterk Merk (LSM), Hasselt University, Ziekenhuis OostLimburg.

CONFLICT OF INTEREST: none declared.

\section{REFERENCES}

1. Effect of enalapril on survival in patients with reduced left ventricular ejection fractions and congestive heart failure. The SOLVD Investigators. N Engl J Med 1991; 325: 293-302.

2. Cohn JN, Johnson G, Ziesche S, Cobb F, Francis $G$, Tristani F, Smith R, Dunkman WB, Loeb H, Wong M, Bhat G, Goldman S, Fletcher RD, Doherty J, Hughes CV, Carson P, Cintron G, Shabetai R, Haakenson C. A comparison of enalapril with hydralazine-isosorbide dinitrate in the treatment of chronic congestive heart failure. N Engl J Med 1991; 325: 303-10.

3. Packer M, Bristow MR, Cohn JN, Colucci WS, Fowler MB, Gilbert EM, Shusterman NH. The effect of carvedilol on morbidity and mortality in patients with chronic heart failure. U.S. Carvedilol Heart Failure Study Group. N Engl J Med 1996; 334: 1349-55.

4. The Cardiac Insufficiency Bisoprolol Study II (CIBIS-II): a randomised trial. Lancet 1999; 353: 9-13.

5. Effect of metoprolol $\mathrm{CR} / \mathrm{XL}$ in chronic heart failure: Metoprolol CR/XL Randomised Intervention Trial in Congestive Heart Failure (MERIT-HF).

Lancet 1999; 353: 2001-7.

6. Packer M, Coats AJ, Fowler MB, Katus HA, Krum H, Mohacsi P, Rouleau JL, Tendera M, Castaigne A, Roecker EB, Schultz MK, DeMets DL; Carvedilol Prospective Randomized Cumulative Survival Study Group. Effect of carvedilol on survival in severe chronic heart failure. N Engl J Med 2001; 344: 1651-8.

7. Flather MD, Shibata MC, Coats AJ, Van Veldhuisen DJ, Parkhomenko A, Borbola J, Cohen-Solal A, Dumitrascu D, Ferrari R, Lechat P, Soler-Soler J, Tavazzi L, Spinarova L, Toman J, Böhm M, Anker SD, Thompson SG, Poole-Wilson PA; SENIORS Investigators. Randomized trial to determine the effect of nebivolol on mortality and cardiovascular hospital admission in elderly patients with heart failure (SENIORS).

Eur Heart J 2005; 26: 215-25.

8. Cohn JN, Tognoni G.

A randomized trial of

the angiotensin-receptor blocker valsartan in chronic heart failure. N Engl J Med 2001; 345: 1667-75.

9. Pfeffer MA, Swedberg K, Granger CB, Held $P_{\text {, }}$ McMurray JJ, Michelson EL, Olofsson B, Ostergren J, Yusuf S, Pocock S; CHARM Investigators and Committees. Effects of candesartan on mortality and morbidity in patients with chronic heart failure: the
CHARM-Overall programme.

Lancet 2003; 362: 759-66.

10. Pitt B, Zannad F, Remme WJ, Cody R, Castaigne A, Perez A, Palensky J, Wittes J. The effect of spironolactone on morbidity and mortality in patients with severe heart failure. Randomized Aldactone Evaluation Study Investigators. NEngl J Med 1999; 341: 709-17.

11. Zannad F, McMurray JJ, Krum H, van Veldhuisen DJ, Swedberg K, Shi H, Vincent J, Pocock SJ, Pitt B. Eplerenone in patients with systolic heart failure and mild symptoms. NEngl J Med 2011; 364: 11-21.

12. Swedberg K, Komajda M, Bohm M, Borer JS, Ford I, Dubost-Brama A, Lerebours G, Tavazzi L. Ivabradine and outcomes in chronic heart failure (SHIFT): a randomised placebo-controlled study. Lancet 2010; 376: 875-85.

13. Bristow MR, Saxon LA, Boehmer J, Krueger $S$, Kass DA, De Marco T, Carson P, DiCarlo L, DeMets D, White BG, DeVries DW, Feldman AM. Cardiac-resynchronization therapy with or without an implantable defibrillator in advanced chronic heart failure. N Engl J Med 2004; 350: 2140-50.

14. Cleland JG, Daubert JC, Erdmann E, Freemantle N, Gras D, Kappenberger L, Tavazzi L. The effect of cardiac resynchronization on morbidity and mortality in heart failure. NEngl J Med 2005; 352: 1539-49.

15. Moss AJ, Hall WJ, Cannom DS, Klein $\mathrm{H}$, Brown MW, Daubert JP, Estes NA 3rd, Foster E, Greenberg H, Higgins SL, Pfeffer MA, Solomon SD, Wilber D, Zareba W. Cardiac-resynchronization therapy for the prevention of heart-failure events. NEngl J Med 2009; 361: 1329-38.

16. Tang AS, Wells GA, Talajic M, Arnold MO, Sheldon R, Connolly S, Hohnloser SH, Nichol G, Birnie DH, Sapp JL, Yee R, Healey JS, Rouleau JL. Cardiac-resynchronization therapy for mild-to-moderate heart failure. N Engl J Med 2010; 363: 2385-95.

17. McMurray JJ, Adamopoulos S, Anker SD, Auricchio A, Böhm M, Dickstein K, Falk V Filippatos G, Fonseca C, Gomez-Sanchez MA, Jaarsma T, Køber L, Lip GY, Maggioni AP, Parkhomenko A, Pieske BM, Popescu BA, Rønnevik PK, Rutten FH, Schwitter J, Seferovic P, Stepinska J, Trindade PT, Voors AA, Zannad F, Zeiher A: Task Force for the Diagnosis and Treatment of Acute and Chronic Heart Failure 2012 of the European Society of Cardiology, Bax JJ, Baumgartner $\mathrm{H}$, Ceconi C, Dean V, Deaton C, Fagard R, Funck-Brentano C,
Hasdai D, Hoes A, Kirchhof P, Knuuti J, Kolh P, McDonagh T, Moulin C, Popescu BA, Reiner Z, Sechtem U, Sirnes PA, Tendera M, Torbicki A, Vahanian A, Windecker S, McDonagh T, Sechtem U, Bonet LA, Avraamides $P$, Ben Lamin HA, Brignole $M$, Coca A, Cowburn P, Dargie H, Elliott $P$, Flachskampf FA, Guida GF, Hardman S, lung B, Merkely B, Mueller C, Nanas JN, Nielsen OW, Orn S, Parissis JT, Ponikowski P; ESC Committee for Practice Guidelines. ESC guidelines for the diagnosis and treatment of acute and chronic heart failure 2012: The Task Force for the Diagnosis and Treatment of Acute and Chronic Heart Failure 2012 of the European Society of Cardiology. Developed in collaboration with the Heart Failure Association (HFA) of the ESC. Eur J Heart Fail 2012; 14: 803-69.

18. Go AS, Mozaffarian D, Roger VL, Benjamin EJ, Berry JD, Borden WB, Bravata DM, Dai S, Ford ES, Fox CS, Franco S, Fullerton HJ, Gillespie C, Hailpern SM, Heit JA, Howard VJ, Huffman MD, Kissela BM, Kittner SJ, Lackland DT, Lichtman JH, Lisabeth LD, Magid D, Marcus GM, Marelli A, Matchar DB, McGuire DK, Mohler ER, Moy CS, Mussolino ME, Nichol G, Paynter NP, Schreiner PJ, Sorlie PD, Stein J, Turan TN, Virani SS, Wong ND, Woo D, Turner MB. Heart disease and stroke statistics--2013 update: a report from the American Heart Association. Circulation 2013; 127: e6-e245.

19. Gheorghiade $M$, Vaduganathan $M$, Fonarow GC, Bonow RO. Rehospitalization for heart failure: problems and perspectives. J Am Coll Cardiol 2013; 61: 391-403.

20. McMurray JJ, Stewart S. The burden of heart failure. Eur Heart J Supp/ 2002; 4: D50-D8.

21. Braunschweig F, Cowie MR, Auricchio A. What are the costs of heart failure? Europace 2011; 13 Suppl 2: ii13-7.

22. Hunt SA, Abraham WT, Chin MH, Feldman AM, Francis GS, Ganiats TG, Jessup M, Konstam MA, Mancini DM, Michl K, Oates JA, Rahko PS, Silver MA, Stevenson LW, Yancy CW. 2009 focused update incorporated into the ACC/AHA 2005 Guidelines for the Diagnosis and Management of Heart Failure in Adults: a report of the American College of Cardiology Foundation/American Heart Association Task Force on Practice Guidelines: developed in collaboration with the International Society for Heart and Lung Transplantation.

Circulation 2009; 119: e391-479. 
23. Jaarsma T, van der Wal MH, Lesman-Leegte I, Luttik ML, Hogenhuis J, Veeger NJ, Sanderman R, Hoes AW, van Gilst WH, Lok DJ, Dunselman PH, Tijssen JG, Hillege $H L$, van Veldhuisen DJ. Effect of moderate or intensive disease management program on outcome in patients with heart failure: Coordinating Study Evaluating Outcomes of Advising and Counseling in Heart Failure (COACH). Arch Intern Med 2008; 168: 316-24.

24. Verbrugge FH, Dupont M, Rivero-Ayerza M, de Vusser $\mathrm{P}$, Van Herendael $\mathrm{H}$, Varcammen J, Jacobs L, Verhaert D, Vandervoort P, Tang WH, Mullens W. Comorbidity significantly affects clinical outcome after cardiac resynchronization therapy regardless of ventricular remodeling. I Card Fail 2012; 18: 845-53.

25. Blecker S, Paul M, Taksler G, Ogedegbe G, Katz S. Heart Failure Associated Hospitalizations in the United States. J Am Coll Card 2013; 61: 1259-67.

26. Mullens W, Kepa J, De Vusser P, Vercammen J, Rivero-Ayerza M, Wagner P, Dens J, Vrolix M Vandervoort $\mathrm{P}$, Tang WH. Importance of adjunctive heart failure optimization immediately after implantation to improve long-term outcomes with cardiac resynchronization therapy. Am J Cardiol 2011; 108: 409-15.

27. Mullens W, Wilson Tang WH Optimizing cardiac resynchronization therapy in advanced heart failure. Congest Heart Fail 2011; 17: 147-51.

28. Mullens W, Grimm RA, Verga T, Dresing T, Starling RC, Wilkoff BL, Tang WH. Insights from a cardiac resynchronization optimization clinic as part of a heart failure disease management program.

J Am Coll Cardiol 2009; 53: 765-73.

29. Binkley PF, Starling RC, Hammer DF, Leier CV. Usefulness of hydralazine to withdraw from dobutamine in severe congestive heart failure. Am J Cardiol 1991; 68: 1103-6.

30. Steimle AE, Stevenson LW Chelimsky-Fallick C, Fonarow GC, Hamilton MA, Moriguchi JD, Kartashov A, Tillisch JH. Sustained hemodynamic efficacy of therapy tailored to reduce filling pressures in survivors with advanced heart failure. Circulation 1997; 96: 1165-72.

31. Rich MW, Beckham V, Wittenberg C, Leven CL, Freedland KE, Carney RM. A multidisciplinary intervention to prevent the readmission of elderly patients with congestive heart failure. N Engl J Med 1995; 333: 1190-5.

32. McAlister FA, Stewart S, Ferrua S, McMurray JJ. Multidisciplinary strategies for the management of heart failure patients at high risk for admission: a systematic review of randomized trials. J Am Coll Cardiol 2004; 44: 810-9.

33. Gonseth J, Guallar-Castillon P, Banegas JR, Rodriguez-Artalejo F. The effectiveness of disease management programmes in reducing hospital re-admission in older patients with heart failure: a systematic review and meta-analysis of published reports. Eur Heart J 2004; 25: 1570-95.

34. Yu DS, Thompson DR, Lee DT. Disease management programmes for older people with heart failure: crucial characteristics which improve post-discharge outcomes. Eur Heart J 2006; 27: 596-612. 